\title{
REPRESENTATIONS OF THE DIGITAL SKILLS OF HIGH SCHOOL STUDENTS: A QUALITATIVE RESEARCH
}

\author{
Claudia Islas Torres, Sergio Franco Casillas, María del Rocío Carranza Alcántar, \\ \& Alma Azucena Jiménez Padilla \\ Centro Universitario de los Altos, Universidad de Guadalajara (México)
}

\begin{abstract}
With the rise of Information and Communication Technologies (ICT) today, digital competencies, for high school students, are necessary skills that must be systematically develop with the awareness of efficient use of ICT. Under this premise, qualitative research was carried out under the interpretative framework of the theory based on the social representations of the students, with the objective of knowing what it represents them to develop these skills in benefit of their formative process. In this sense, an in-depth interview validated by experts, was conduct to eighteen high school students. With this technique, we sought to identify how students recognize their skills in the use of technologies, how they apply them in their learning process, and what they represent for them. Researchers used ISTE Standards as dimensions for the categorization of data about creativity and innovation, communication and collaboration, research and information management, critical thinking, problem solving and decision-making, digital citizenship, and operations and ICT concepts. The results indicate that students recognize having skills for the management of technologies, however, these are not channeled in the sense of benefiting their training process since there is little participation in the creation of materials for the construction of knowledge. Likewise, they recognize the applicability of technologies for collaboration and communication, but they do not apply them as such, the use of ICT is direct to social and recreational issues than for the purposes of academic interaction and collaborative learning. They refer to the little formality which they carry out their investigations and manage the information, they do not apply processes of critical analysis, selection and evaluation of the information they consult. The development of critical thinking is limited, and they do not reach the solution of problems and decision-making based on accurate information. About digital citizenship, students are aware of the importance of using ICT in a responsible, ethical and safe way, however, they have fallen into plagiarism, cyberbullying and among other. Students recognize that technologies can support them according to their needs for knowledge acquisition and transfer, although they know that it is essential to use habits that lead them to the productive use of the tools and content provided by ICT. It is necessary to continue carrying out this type of research that provides empirical information about this subject.
\end{abstract}

Keywords: Grounded theory, social representations, digital competences, high school students, qualitative research.

\section{Introduction}

Information and communication technologies (ICT) have been present in all areas of educational levels, and high school students are no exception. Therefore, the incidence of technologies originates the evolution of skills developed by those who access them, either with the Internet from desktop or mobile devices, or through the consumption of information that people accesses excessively in computer systems. In this sense, students, who attend the high school are involved in a dynamic system, in which teachers, students and educational contents are implicated through the interactions between them (Islas, Zavala, \& Carranza, 2018). Thus, the formative processes have been modified, forcing the main actors to focus on a different role-play from the one carried out in traditional teaching.

This is in addition to what is indicated in the NETS.S project (ISTE Standards, 2016) where the standards that students had to develop to become proficient in the use of ICT, and in the critical development of skills that would strengthen their personal productivity, as creativity, critical thinking and collaboration, both in classroom and in everyday life. 
The ISTE Standards encompass six dimensions that guided the realization of this research project. They are listed below:

1. Creativity and innovation: students are evaluated if they demonstrate creative thinking, building new knowledge or generating innovative ideas that lead them to identify new trends and forms of expression either individual or group.

2. Communication and collaboration: students use media and technological environments for collaboration and communication in an efficient and productive way, at the same time, they generate their own knowledge and expose it in different scenarios and media.

3. Research and information management: It is valued if students have developed the ability to obtain, evaluate and use information in a planned and organized way through reliable sources and especially from scientific or academic areas.

4. Critical thinking, problem solving and decision-making: In this case, students should have sufficient skills to apply their critical thinking and give meaning to what they investigate from the information they consult, applying what they found in solving problems or decision making to increase their ability of acquiring and managing their knowledge.

5. Digital citizenship: Students know how to behave in an ethical, responsible and legal manner when they are using or disseminating information, and where they can show positive behaviors when they face with the use of TIC.

6. Concepts and functioning about ICT: Students demonstrate having the skills, knowledge and understanding of the appropriate use of information, devices and applications that the technologies imply, in such a way, they develop skills for their use efficient and effective of them.

Under these premises, this research project was developed and we only consider the digital competences of the students, following a qualitative approach under the interpretive framework of the grounded theory and the social representations of the students, in order to know what it means for them to develop these skills in benefit of their training process about digital competences.

Under this assumption, for approaching, the phenomenon of the development and applicability of digital competences by high school students was used the Grounded Theory. This epistemic foundation is a different approach to social reality according to Glaser and Strauss who are pioneers of this theory and the truth of scientific results arises from the observation and emerging consensus of a set of scientists who give some meaning to the phenomenon observed (Páramo, 2015). On the other hand, the empirical reality is conceived as a result of the meanings produced by some people who are inserted in common observation projects (Suddaby, 2006), and through of constant comparison produce data that allow the identification of theoretical categories emerging from the comparative analysis of various interviews or episodes of the observation. Researchers, of this project, found some coincidences in the analysis and comparison of the obtained data in the interviews of the students and what the standards mark. In this sense, the understanding of the observed in the interviews and the phenomenon studied were reached, taking also as an interpretive foundation the framework of social representations.

In this context, social representations work as an adequate reference for the study of educational phenomena since they allow giving intelligibility to the daily relationships between exchanges and imagination of the actors (Mora, 2002). Moscovici, the precursor of this conceptualized theory, who shows it as a cognitive expression where people construct with their own logic and language, and it implies their beliefs, values and ideas that allows individual reality and generate knowledge that affects their thinking and the organization of their everyday life. Therefore, social representations are a concrete way to communicate and understand about knowledge to analyze people behaviors and to predict them.

In the field of education, social representations have served to understand the behavior of teachers and students in certain situations, leading to the conclusion that beliefs, interactions or perceptions are incidents in the practice of those who are involved in the formative processes (Mora, 2002). Therefore, this interpretative framework allows moving from the elaboration of concepts to the construction of new theories, since they constitute a unit of focus that integrates the individual and collective, the symbolic and social, and thought and action (Chourio, 2012). In this sense, the usefulness of social representations is conceived before the possibility of synthesizing the explanations that people make about their reality, to what they think and live.

Thus, by adding both interpretative frameworks, social representations and digital competences, it was possible to rescue the figurative and subjective core that students give to their digital competences based on how they apply value and conceive them.

\section{Design}

This research project is qualitative then the size of the sample is not determined in probabilistic terms (Hernández, Fernández, \& Baptista, 2013) because it is an in-depth research where 18 high school 
students were interviewed. Researchers were interested in the arguments of what digital competences represent for the high school students and how they apply them in their daily live. To achieve this, it was necessary to clarify to the participants that the questions asked in the interview were only to collect data that would be treated scientifically and that their personal information would remain anonymous, so this allowed greater confidence and availability of the participants.

The interviewees were nine men and nine women, to maintain the representatives sample of them in the interview, we selected three students of the different high school grades, that it allowed to balance the gender and the experience of each one. The sample was a convenience of the researchers.

This research was conducted in public schools in a city in the state of Jalisco, Mexico, following the principles of qualitative research under the interpretative frameworks of grounded theory and social representations.

\section{Objectives}

To know what represents for the high school students the development of digital competences to benefit their own educational process.

\section{Methods}

- In-deep interview.

- Applying the constant comparative method from the grounded theory.

- Applying social interpretive framework from social representations method.

- Unit of analysis: digital competences developed by the students and representation of them in the development of their learning.

\section{Results}

The results indicate that students recognize having skills for the management of technologies, however, these are not channeled in the sense of benefiting the students learning process since there is little participation in the creation of materials for the construction of knowledge. They also recognize the applicability of technologies for collaboration and communication, but they do not use them in an effective way, their use is more directed to social and recreational issues than for the academic purpose in the interaction and collaborative learning process. They refer to the little formality which they carry out their investigations and manage the information, they do not apply processes of critical analysis, selection and evaluation of the contents they consult. The development of critical thinking is limited, and they do not give the solution of problems and the decision-making is not based on accurate information. In terms of digital citizenship, students are aware of the importance of using ICT in a responsible, ethical and safe way, however, they have fallen into plagiarism, cyber-bulling and other bad practices about the use of information. Students recognize that technologies can support them according to their acquisition and transfer needs of knowledge, although they know that it is essential to have habits that lead them to the productive use of the tools and content provided by ICT.

Figure 1. Representation of the students. Source: Own creation.

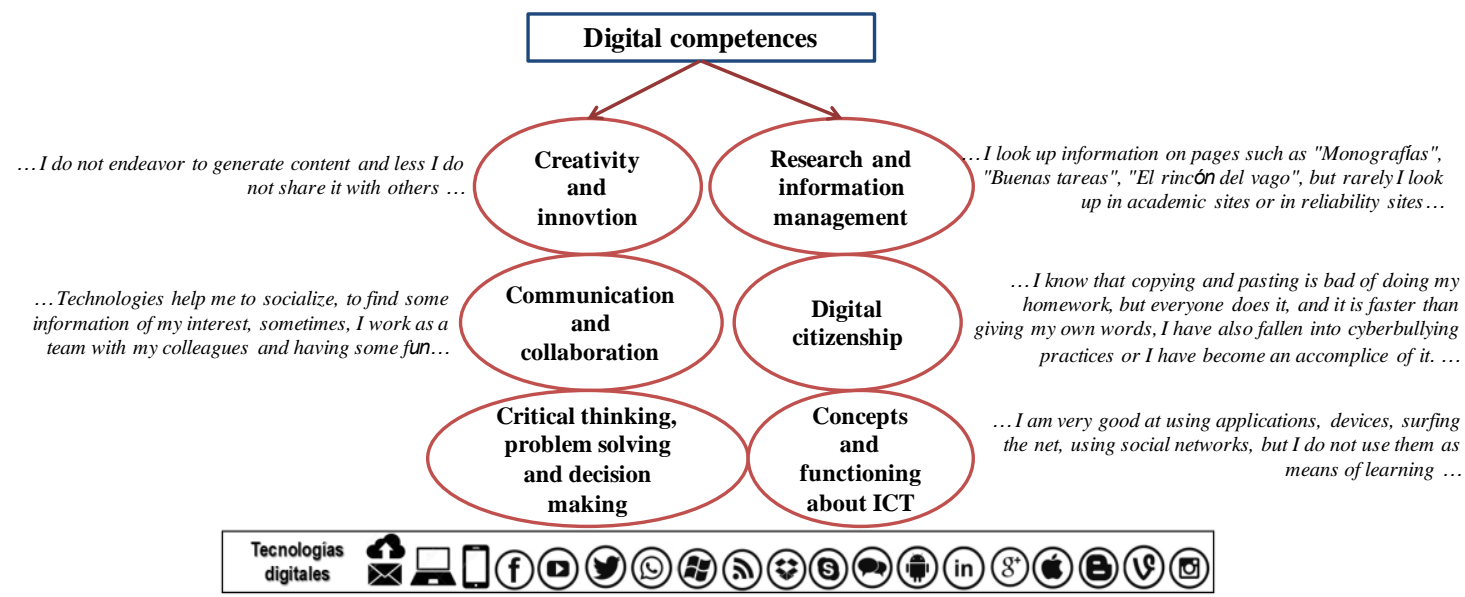




\section{Discussion and conclusions}

The role of ICT, in educational context, has become an object of study from different positions, visions and interpretations; however, it is convenient that researches also focus on recognizing the articulation of technologies and the development of skills for their appropriate management. The applicability of ICT has favored the learning of students in different levels.

After this investigation, it was possible to identify that there are no learning benefits or high content structure in terms of complexity and depth, the copying and pasting practices and not respecting copyrights become common, the sites that students always visit are "Buenas Tareas", "Rincón del Vago", and, in very few cases, "academia.edu" or "Google academic". Good practices about working in collaborative way exist, although there are not in a greater proportion or quality, there is laziness or lack of willingness for being productive and going beyond the simple domain in the use of technologies and it is still notorious.

In terms of skills, they are considered skillful themselves and they make it notice, although, they do not trespass the barrier of social and fun to the benefit of their own knowledge, this finding coincides with the expressed by López (2014); Hicks (2011); Kinchin (2012); and Tompsett (2013) cited in Universidad Javeriana (2016).

It is noteworthy to indicate that the expectations regarding about digital competences, that students can develop, have generally been higher than what actually happens, and this can be attributed to adverse situations that not only depend on them, but also on the participation of teachers, educational authorities, and the education system. A clear consensus has not been reached yet, about what technologies are in the educational field.

There is no doubt that ICT are indispensable tools in today live, it is necessary to know their limits and scope of them, especially if it is based on the standards in ICT competences. Students are empowered to those skills that have to do with cognition and metacognition of who uses them, in addition to the values and skills that can be put into practice.

As is well known, ICT have the potential of working as psychological tools that mediate the processes of people interaction, therefore, their mediating role is recognized by the interactive triangle that is generated. The benefits of their potential are understood when there is clarity and awareness in those people who use them and they know how to act with or without them, so the scenarios that are configured mean an opportunity to play the dynamics role between the ICT and today society demands.

It is important to continue developing this kind of researches, where quality is given to the information found since the numbers and statistics of access and infrastructure are no longer enough, it must be passed on to the production of empirical knowledge that shows the advantage of including technologies in the training processes.

In the same way, it is necessary to emphasize that the educational system, at least in Mexico, must become aware of the need to disintegrate archaic structures in the teaching-learning processes. To give way to renewed techniques where students and teachers are aware of the importance of development of digital competences that enhance their intellectual and integral growth, to face the challenges that the changing world in which they are immersed demands them.

The formative processes must be structured in such a way that they prepare the students to face the challenges of daily life and advance beyond them to form them for life. The use of ICT gives them this possibility, since mental structures are no longer the same and unrestricted access to information requires skills superior to those developed a few decades ago. Therefore, it is important to promote creativity, critical thinking, the ability to solve problems, and the ability of making decisions, as well as they need to know about ethics about the use of digital media to respect the information that comes from them.

\section{References}

Chourio, N. (2012). Teoría de las representaciones sociales: discusión epistemológica y metodológica. Estudios culturales (10).

Hernández, R., Fernández, C., \& Baptista, P. (2013). Metodología de la investigación. México: McGrawHill.

Islas, C., Zavala, S., \& Carranza, M. D. (2018). Los ecosistemas digitales para estudiantes de bachillerato: un estudio mixto. En M. Prieto, S. Pech, \& J. A. Francesa-Alfaro, Tecnologías y Aprendizaje: Investigación y Práctica (págs. 428-436). Ciudad Real España: CIATA.Org. 
ISTE Standars. (2016). ISTE. From https://info.iste.org/student-standards-get-posterthanks?submissionGuid=e942d79e-6635-40d3-ab29-cfe13b9c7660

López, M. (2014). Aprendizaje, competencias y TIC. México: Pearson.

Mora, M. (2002). La teoría de las representaciones de Serge Mscovici. Athenea Digital (2).

Páramo, D. (2015). La teoría fundamentada, metodología cualitativa de investigación científica. Pensamiento y Gestión (39), 119-146.

Suddaby, R. (2006). What Grounded Theory is not. The academy of management journal, 49 (4), 633-642.

Universidad Javeriana. (2016). Competencias y estándares TIC desde la dimensión pedagógica: Una perspectiva de los niveles de apropiación de las TIC en la práctica educativa docente. Colombia: Universidad Javeriana. 